\title{
Changes in the Distribution of the Neuron-Specific B-50, Neurofilament Protein and Glial Fibrillary Acidic Proteins Following an Unilateral Mesencephalic Lesion in the Rat
}

\author{
A. B. OESTREICHER, P. DEVAY,* R. L. ISAACSON $\dagger$ AND W. H. GISPEN ${ }^{1}$ \\ Division of Molecular Neurobiology, Rudolf Magnus Institute for Pharmacology \\ and Institute of Molecular Biology and Medical Biotechnology \\ Padualaan 8, 3584 CH Utrecht. The Netherlands \\ *Institute of Enzymology, Biological Research Center \\ Hungarian Academy of Sciences, Budapest, Hungary \\ $\dagger$ University Center at Binghamton, Center for Neurobehavioral Sciences \\ and Department of Psychology, Binghamton, 13901
}

Received 23 November 1987

\begin{abstract}
OESTREICHER, A. B., P. DEVAY, R. L. ISAACSON AND W. H. GISPEN. Changes in the distribution of the neuron-specific B-50, neurofilament protein and glial fibrillary acidic proteins following an unilateral mesencephalic lesion in the rat. BRAIN RES BULL 21(5) 713-722, 1988.-Following a unilateral electrolytic lesion in the ventral rat mesencephalon, changes in the immunocytochemical distribution of the neuron-specific B-50, neurofilament (NF) protein and glial fibrillary acidic (GFAP) proteins were studied around the lesion after $0,3,10$ and 28 days. At all recovery times, the controls displayed on immunostaining with anti-B-50 and anti-neurofilament antibodies, a characteristic pattern of synaptic and neuritic localization of these antigens, whereas anti-GFAP staining revealed a distribution typical for astrocytes. The lesion was characterized by a center of coagulated material that exhibited immunoreactivity to B-50 (BIR) and NF (NFIR), but never GFAP-immunoreactivity. From 3 days on, the center became surrounded by disintegrating cells which were unreactive to the antibodies. The antigen distribution changed temporally, predominantly at the lesion rim. By 10 and 28 days postlesion, additional BIR was observed as punctuate dots in fibers and membranes of neurons. Enhanced NFIR was detected in fibers and cell bodies. Many astrocytes were detected around the lesion rim, forming by 28 days postsurgery a barrier between the lesion cavity and the uninjured tissue. Our study shows that distribution changes in B-50, NF and GFAP around the lesion may indicate local degenerative and adaptative processes as a temporal response to brain trauma.
\end{abstract}

Brain lesion Phosphoproteins Neuron-specific Phosphoprotein B-50 GAP43 Immunocytochemistry Neuroplasticity

THE neuron-specific protein B-50 is a major substrate to protein kinase $\mathrm{C}$ in growth cones, neonatal neural and adult synaptosomal plasma membranes $(6,21,22)$ and in outgrowing processes of differentiated PC12 cells (32). Studies reported by various laboratories (2) revealed that the protein B-50 is identical to GAP43 (13,41), GAP48 (25), F1 (8) and pp46 $(19,26)$. Molecular cloning studies have confirmed the identity and shown that B-50 is a very hydrophylic $23.6 \mathrm{kDa}$ protein consisting of 225 amino acid residues (20). Currently this protein is being studied as a specific marker of axonal outgrowth in development (9) and postlesion regeneration
(37). Whereas many studies have reported the consequences of a brain lesion concerning alterations in the projection field of the injured neurons $(1,15,27)$, our study describes events in the tissue bordering the lesion as observed in frozen brain sections cut horizontally through the lesioned area.

The aim of the study was to describe the fate of specific neuronal glial markers at the site of injury. In keeping with literature we describe the neural response to damage in terms of postlesion plasticity, comprising both degenerative and regenerative processes. The assumption was that regenerative processes would be characterized by enhanced

${ }^{1}$ Requests for reprints should be addressed to W. H. Gispen. 


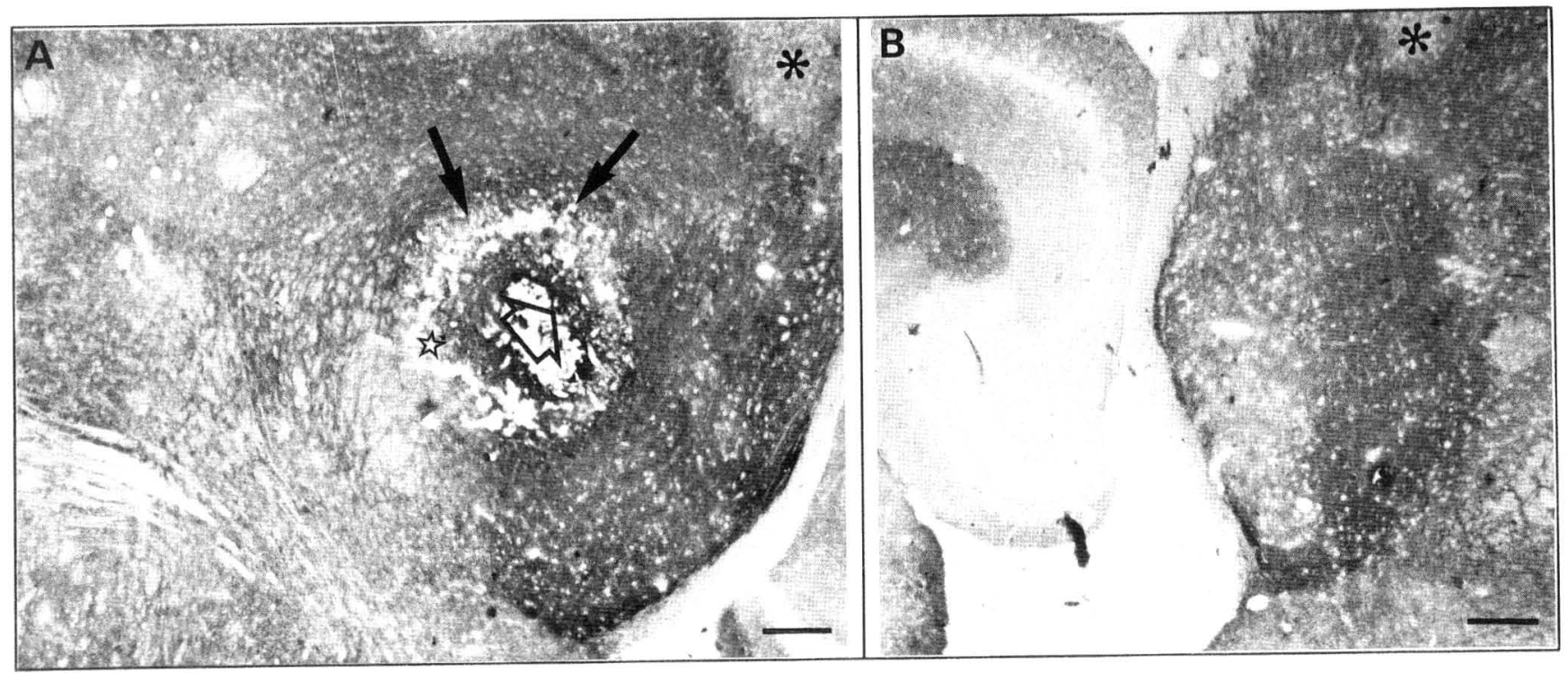

FIG 1. (A) Micrograph of the distribution of B-50 immunoreactivity (BIR) at the lesion site in a horizontal section of the ventral mesencephalon prepared a few hours after the induction of the unilateral lesion at day 1 . Note the intense staining in the center (arrow outline) of the lesion. adjacent to diminished staining of destructed tissue with holes (open star) and bordering to intact tissue (black arrows). The intact surrounding tissue revealed a characteristic BIR pattern corresponding to its presumed axon terminal and synaptic localization, rather similar to the contralateral side (1B, black stars). Bar is $420 \mu \mathrm{m}$.

immunostaining of B-50 and neurofilament in fibers, whereas degeneration would result in amorphous accumulation of neuronal markers and gliosis. Over a recovery period of 28 days, we explored and inventoried in the rat, at 4 time points, the immunocytochemical distribution of B-50 at the rim of an unilateral ventral mesencephalic lesion, induced by electrolytic coagulation in the rat. In parallel, we compared the immunocytochemical distribution changes of NF, as a cytoskeletal marker for neurons, and GFAP as a marker for reactive gliosis. An attempt was made to describe the immunocytochemical changes in terms of distinct manifestations of de- and regeneration.

\section{METHOD}

\section{Chemicals}

All chemicals used were of analytical grade. Specific immunoreagents were as follows: rabbit antiserum to cow glial fibrillary acidic protein (a-GFAP) and rabbit anti-mouse immunoglobulins (IgGs) conjugated to horse radish peroxidase were purchased from Dakopatts (Denmark); mouse monoclonal anti-human neurofilament protein antibodies (a-NF), reactive with the $70 \mathrm{kDa}$ and $200 \mathrm{kDa}$ polypeptides, clone 2F11 from Monosan, Sanbio (Leiden, NL); Vectastain ABC kit (Burlingame, CA) and affinity-purified rabbit anti-rat B-50 antibodies (a-B-50 IgGs) were prepared from antiserum 8420 , as described previously by Oestreicher et al. (23).

\section{Surgical Procedure}

Male rats of an inbred Wistar strain (TNO, Zeist, NL; body weight $150 \mathrm{~g}$ ) were subjected to an unilateral electrolytic lesion in the mesencephalon close to the substantia nigra. The animals were anaesthetized with $0.1 \mathrm{ml} \mathrm{Hypnorm}{ }^{B}$ (Philips Duphar, NL) per $150 \mathrm{~g}$ body weight. They were placed in a stereotaxic appratus. After opening the skull, an insulated $0.2 \mathrm{~mm}$ thick stainless steel electrode was intro- duced to a point calculated according to coordinates derived from the atlas of König and Klippel [(17), Fig. 45b]: the distance was $2.42 \mathrm{~mm}$ anterior to the interaural plane, 2.0 $\mathrm{mm}$ lateral from FLC (fissura longitudinalis cerebri) and 2.6 $\mathrm{mm}$ ventral to the horizontal zero plane. A radiofrequency current of $20 \mathrm{~mA}$ at 70 volt was sent for $30 \mathrm{sec}$ through the uninsolated $1 \mathrm{~mm}$ electrode tip. A group of 4 rats was subjected to sham-lesion procedures, performing the surgical procedure used in the lesion group, but omitting the electric current.

\section{Tissue Preparation}

On the day of surgery, a few hours after the procedure was completed, two rats (day 1) were sacrificed. The other groups of rats $(\mathrm{n}=5)$ were allowed to survive and were sacrificed at day 3,10 , and 28 . The sham-lesioned animals were allowed to survive for 10 days. The rats were anaesthetized and transcardially perfused with $300 \mathrm{ml}$ of fixative containing $2 \%(\mathrm{w} / \mathrm{v})$ paraformaldehyde, $0.5 \%(\mathrm{w} / \mathrm{v})$ glutaraldehyde, $0.1 \%(\mathrm{v} / \mathrm{v})$ dimethylsulfoxide in phosphate-buffered saline (PBS). After perfusion, the brains were removed from the skull and immersed in the fixative for $16 \mathrm{hr}$ before being washed for $30 \mathrm{~min}$ at room temperature in PBS containing $0.1 \mathrm{M}$ glycine. The fixed brains were cryoprotected by immersion in a series of sucrose solutions of increasing concentration: $7.5 \%$ and $15 \%(\mathrm{w} / \mathrm{v})$ each for $3 \mathrm{hr}$, and $25 \%(\mathrm{w} / \mathrm{v})$ overnight. Frozen brains were horizontally sectioned at minus $16-20^{\circ} \mathrm{C}$ at $10 \mu \mathrm{m}$ thickness. Starting at approximate "Bregma $6.6 \mathrm{~mm}$ " [approximately the level of Fig. 58 of Paxinos and Watson, (24)] to "Bregma $8.7 \mathrm{~mm}$ " [approximately Fig. 54 of Paxinos and Watson, (24)] 3 tissue sections out of every 5-10 were collected on previously coated microscope slides [coating: $1.5 \%(\mathrm{w} / \mathrm{v})$ gelatin, $30 \%(\mathrm{v} / \mathrm{v})$ ethanol, $0.1 \%(\mathrm{w} / \mathrm{v})$ chrome-potassium sulphate, $7 \%(\mathrm{v} / \mathrm{v})$ acetic acid] and stored at $-20^{\circ} \mathrm{C}$. 


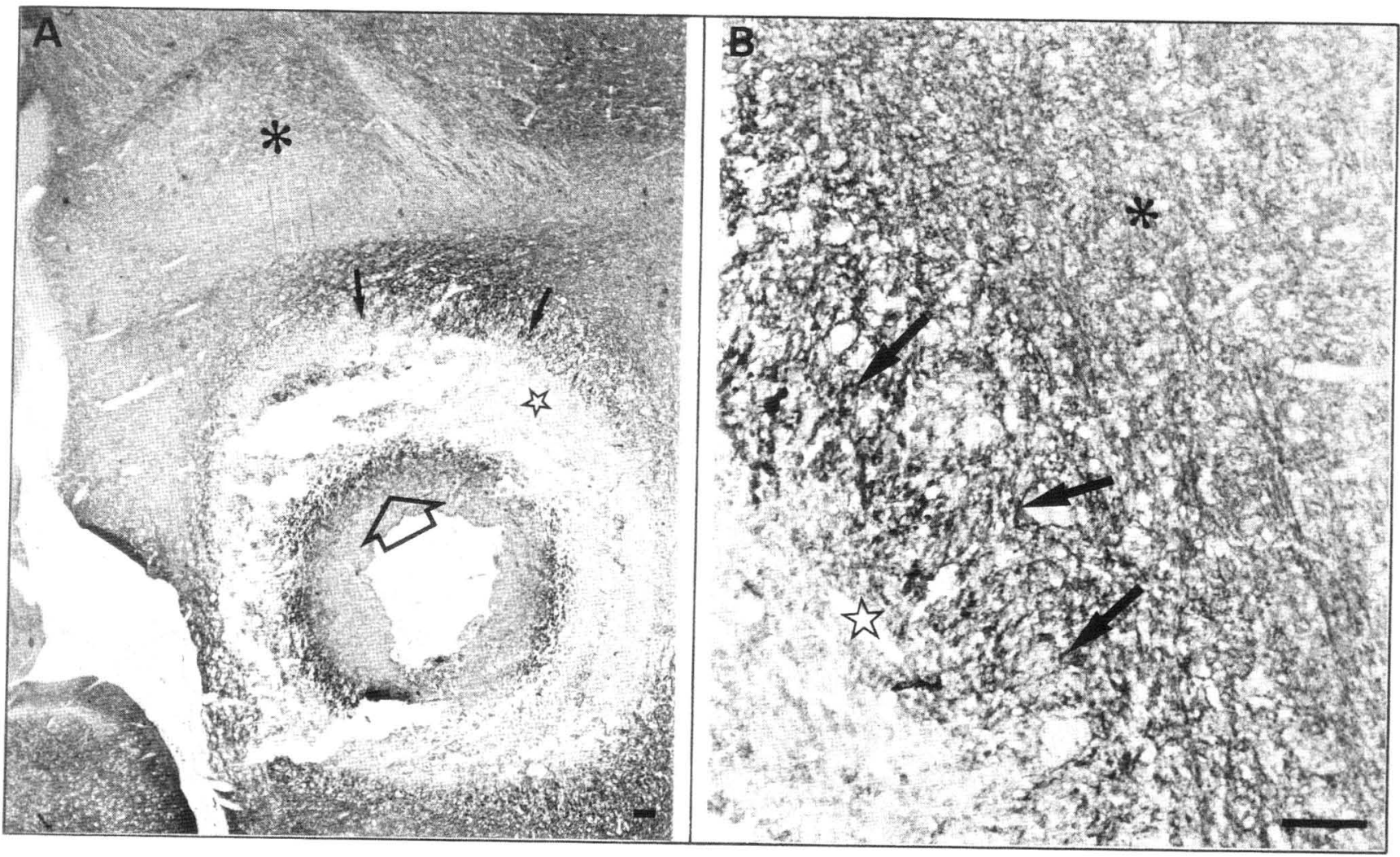

FIG. 2. BIR distribution 3 days postlesion. Panel A shows a differential staining pattern with intense BIR in the center part (arrow outline) (black arrows) was present. The intact tissue showed cells (open star). At the rim of the lesion (panel B), intense BIR in fiber-like material (black star). Bar is $100 \mu \mathrm{m}$.

\section{Immunocytochemical Procedure}

Tissue sections were dehydrated and incubated in $0.5 \%$ $\mathrm{H}_{2} \mathrm{O}_{2}$ diluted in methanol for $30 \mathrm{~min}$ to destroy endogenous peroxidase activity. After this treatment, the sections were rehydrated, washed in $\mathrm{PBS}$ for $20 \mathrm{~min}$, and subjected to one of the immunostaining procedures. Controls for specific staining were incubations omitting the primary antibodies and with purified B-50 preabsorbed anti-B-50-IgGs. The controls showed hardly any background staining.

\section{Immunostaining for B-50 Protein and GFAP}

The sections were incubated with normal goat serum (dilution 1:74) for $20 \mathrm{~min}$ and then with primary antibody for B-50 protein (rabbit anti-B-50 IgGs in dilution 1:2000 or $1: 4000$ ) or for GFAP (rabbit anti-cow GFAP, in dilution 1:800 or 1:1600) overnight at room temperature. Dilutions of serum and antibodies were made in PBS containing $0.1 \%(\mathrm{w} / \mathrm{v})$ bovine serum albumin (BSA). After thoroughly rinsing in PBS sections were washed 3 times for $10 \mathrm{~min}$.

The sites of binding were detected by means of the reagents of the Vectastain ABC kit (12). First, incubation for 60 min with biotinylated secondary antibody (dilution 1:222) was carried out and then, after extensive rinsing $(3 \times 10 \mathrm{~min})$ in PBS, incubation followed with avidin-biotin complex conjugated to peroxidase (dilution 1:111) for $60 \mathrm{~min}$. After rinsing $(3 \times 10 \mathrm{~min})$ the peroxidase reaction was carried out in a filtered solution of $0.05 \%(\mathrm{w} / \mathrm{v}) 3,3^{\prime}, 4,4^{\prime}$-diaminobenzidine hydrochloride in $0.05 \mathrm{M}$ Tris buffer at $\mathrm{pH} 7.6$ containing $0.01 \% \mathrm{H}_{2} \mathrm{O}_{2}$. The enzyme reaction was stopped by extensive rinsing with distilled water. In some instances sections were contra-stained with hematoxylin. Finally, sections were dehydrated and coverslipped with Depex (Serva, Switzerland).

\section{Immunostaining with a-NF}

Sections were incubated with normal rabbit serum (dilution $1: 10)$ and then with primary monoclonal mouse antibody to NF (dilution 1:20) overnight at room temperature. After rinsing in Tris-buffered saline (TBS), peroxidase-conjugated secondary rabbit anti-mouse antibodies (dilution 1:2000) were applied for $60 \mathrm{~min}$ to the sections. After rinsing in TBS, the peroxidase reaction was developed and the sections were contra-stained, as described above.

\section{RESULTS}

\section{Immunocytochemical Studies}

Horizontal tissue sections obtained from the rats sacrificed a few hours after surgery, processed and stained for B-50, showed that the left ventral mesencephalon (Fig. 1A) contained a lesion of disorganized material with a crosssection of approximately $1500 \mu \mathrm{m}$ amidst apparently normal cytoarchitecture. The very center consisted of a hole surrounded by unstructured seemingly coagulated material with intense BIR (Fig. 1A, arrow outline). Adjacent to the heavily stained central area, the immunostaining diminished and changed to a concentric region of highly vacuolized tissue (black arrows) that bordered the unaffected tissue. The unaffected surrounding tissue (e.g., black stars in Fig. 1A and B) revealed a characteristic pattern of BIR dots correspond- 

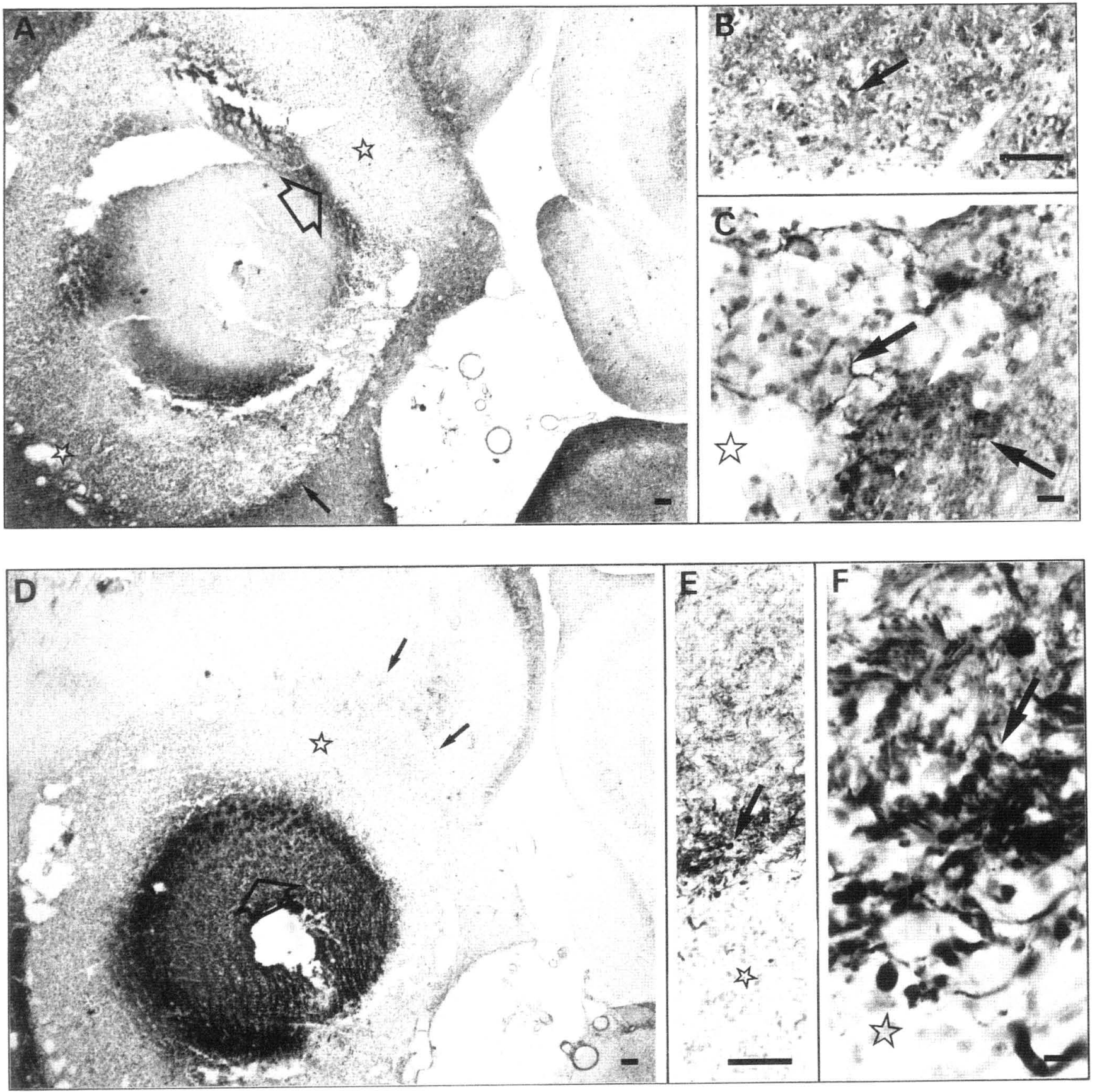

Fig. 3. CONTINUED ON FACING PAGE

FIG. 3. Photomicrograph of the cytoarchitecture around the lesion 10 days after the operation as detected by immunocytochemistry of B-50 ( A,B and C) and neurofilament (NF,D,E and F), as neuronal markers, and of glial fibrillary acidic protein (GFAP, G and H) as the glial marker, all in contrastained sections. Panel A shows that intense BIR consisting of degenerating fibers and neuropil, was present in the interior of the lesion (arrow outline), surrounded by immuno-negative disintegrating cells (open star). At the lesion rim bordering the unaffected tissue (black lesion (arrow outline), surrounded by immuno-negativ (black arrows) was displayed in profiles resembling fibers (Fig. 3C, black arrows). The lesion beyond the decaying immuno-negative cells (open stars), intense NFIR in fibers and a few neurons (Fig. 3F, black arrow) was present. In contrast, the immunoreactivity to GFAP (GIR, Fig. 3G, arrow outline) was sparse in the center of the lesion and in the region of the decaying cells (open star). GIR was concentrated in astrocyte processes and soma at the lesion rim (black arrows in $\mathrm{G}$ and $\mathrm{H}$ ) and, in addition, more pronounced in the intact tissue close to the lesion. Bar is $100 \mu \mathrm{m}$, except in Fig. 3C, F, where bar is $10 \mu \mathrm{m}$. 


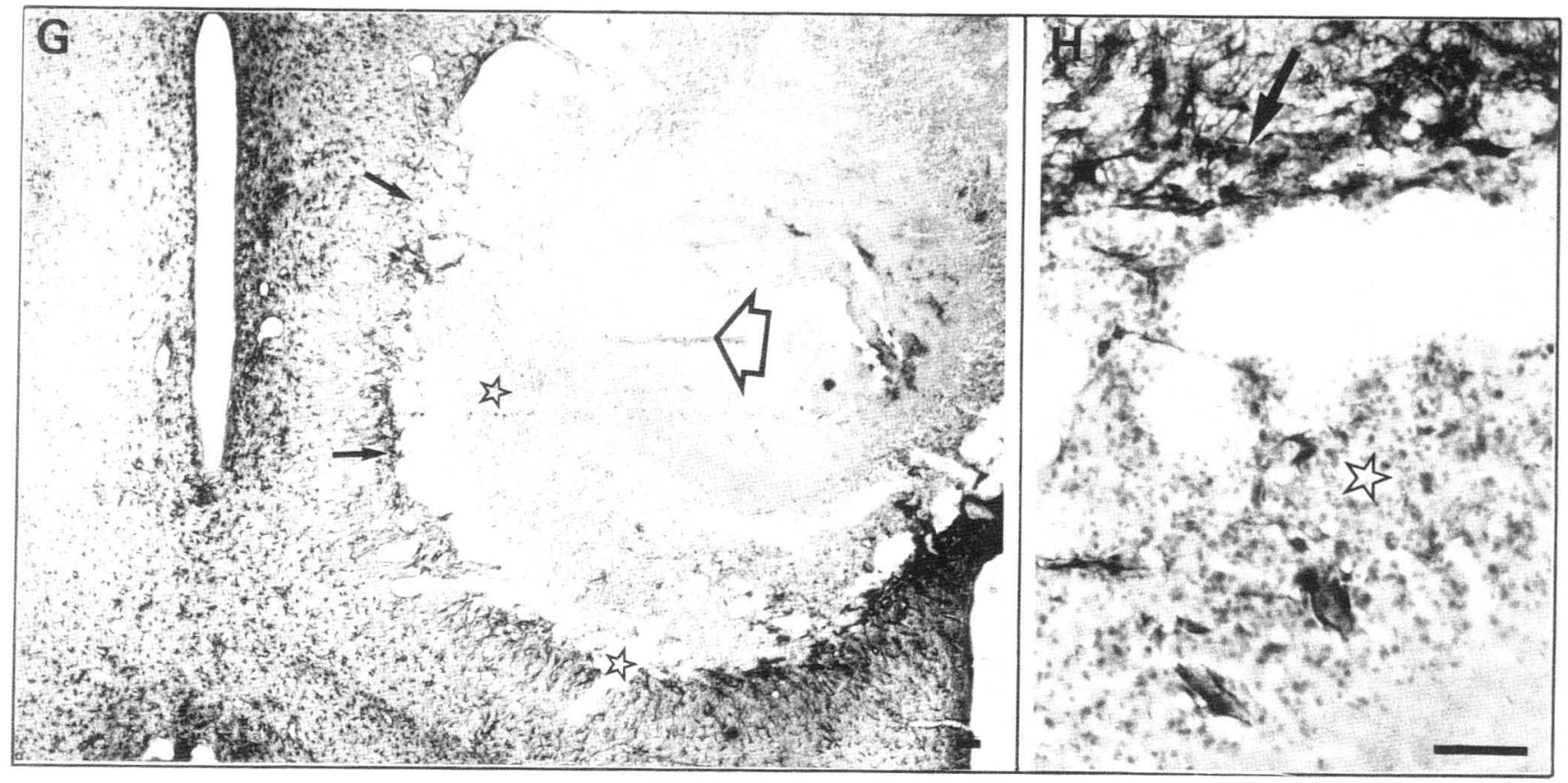

ing to presumed axon terminal and synaptic localization. The intact regions on the contralateral mesencephalon (Fig. 1B) and the same regions of the sham-operated animals demonstrated similar BIR distributions. In addition, the distribution of BIR in the hippocampi of both sides showed a laminar organization corresponding to that reported previously (22). Cells were rarely stained by anti-B-50. The complete complement of cells was visualized by staining with hematoxylin (data not shown, but see Fig. 3).

At 3 days postlesion, the injured area had extended to 1.5-2-fold the size seen a few hours after surgery. The center of the lesion consisted of a hole surrounded by moderately immunostained material (Fig. 2A, arrow outline). Beyond this, there was a region of loosely connected cells (Fig. 2A, open star; identified by contrastaining with hematoxylin of the nuclei of these cells in other sections, data not shown). This "halo" of apparently disintegrating tissue did not react with the three antibodies tested. More distant from the center, there was an affected cell dense region revealing intense BIR in material with a fibrous appearance, possibly indicating neuritic sprouting (Fig. 2B, black arrows). This region bordered intact tissue (black stars) that revealed the typical neuropil pattern of BIR also seen in the contralateral side.

Figure 3 shows immunostaining by three antibodies of sections obtained after 10 days of survival. The size of the lesion was similar to that seen after 3 days but the structure had changed. The "affected" tissue, including the "halo", (open stars), became distinguished from the unaffected surrounding tissue by increased vacuolization at the outer rim of the lesion (for overview see Fig. 3A, D, G). Near the center of the lesion, BIR was present in degenerating material (Fig. $3 \mathrm{~A}$, arrow outline). The lesion center was also stained intensely with anti-NF antibodies. Reacting with the 70 and $200 \mathrm{kDa}$ subunits (35) destructed material and fiber fragments were revealed (Fig. 3D, arrow outline). In contrast, staining the anti-GFAP was not observed in the lesion center, but was present at the lesion rim (Fig. $3 \mathrm{G}$ and $\mathrm{H}$, black arrows) and the parts where intact tissue was connected with the dense disintegrating tissue (Fig. $3 \mathrm{H}$ ). At the border region of disintegrating (open stars) and unaffected tissue, intense BIR was displayed in dots along short fibers and on the plasma membrane of cells (Fig. 3B and C, black arrows), but not in the interior of the "halo" (Fig. 3A). A similar intense neurofilament immunoreactivity (NFIR) was observed in fibers and some cells at the lesion border (Fig. 3E, arrow outline and $3 \mathrm{~F}$, black arrows). The enhanced BIR and NFIR, markers for axonal sprouting, suggest a neuroplastic response occurring at the lesion rim after 10 days of survival. In addition, a marked gliosis had developed in the uninjured surrounding tissue, particularly along the border of the lesion (Fig. $3 \mathrm{G}$ and $\mathrm{H}$ ). However, while gliosis was extensive at the lesion border, the lesion was not yet completely encapsulated by astrocytes or their processes at this time after surgery.

We followed the immunocytochemical changes till 28 days postsurgery, when the lesion had become strongly demarcated by a astrocytic border as revealed by staining with anti-GFAP (Fig. 4E,F, fat black arrow). Ipsilateral areas at some distance from the lesion rim contained relatively more stained astrocytes than detected on the opposite, uninjured side at homologous location. BIR (Fig. 4A,B) and NFIR (Fig. 4C,D) were still intense at locations in the lesion interior (arrow outline) and at the edge of the lesion (black arrows). This enhanced B-50 immunostaining (see also Fig. 5), on top of the characteristic neuropil staining pattern, as seen at the collateral side, may refer to processes of neuronal adaptation and compensation. Figure $5 \mathrm{~A}$ shows the appearance of BIR at the lesion rim in fiber-like profiles (black arrows) after 10 days of survival. After 28 days, BIR was also detected in dot-like deposits (black arrows), revealing presumably synaptic locations (see Fig. 5B). Little difference was detected in neuropil staining pattern of anti-B-50 and anti-NF between the uninjured areas of the left and right mesencephalic regions (data not shown). Possible minor ad- 

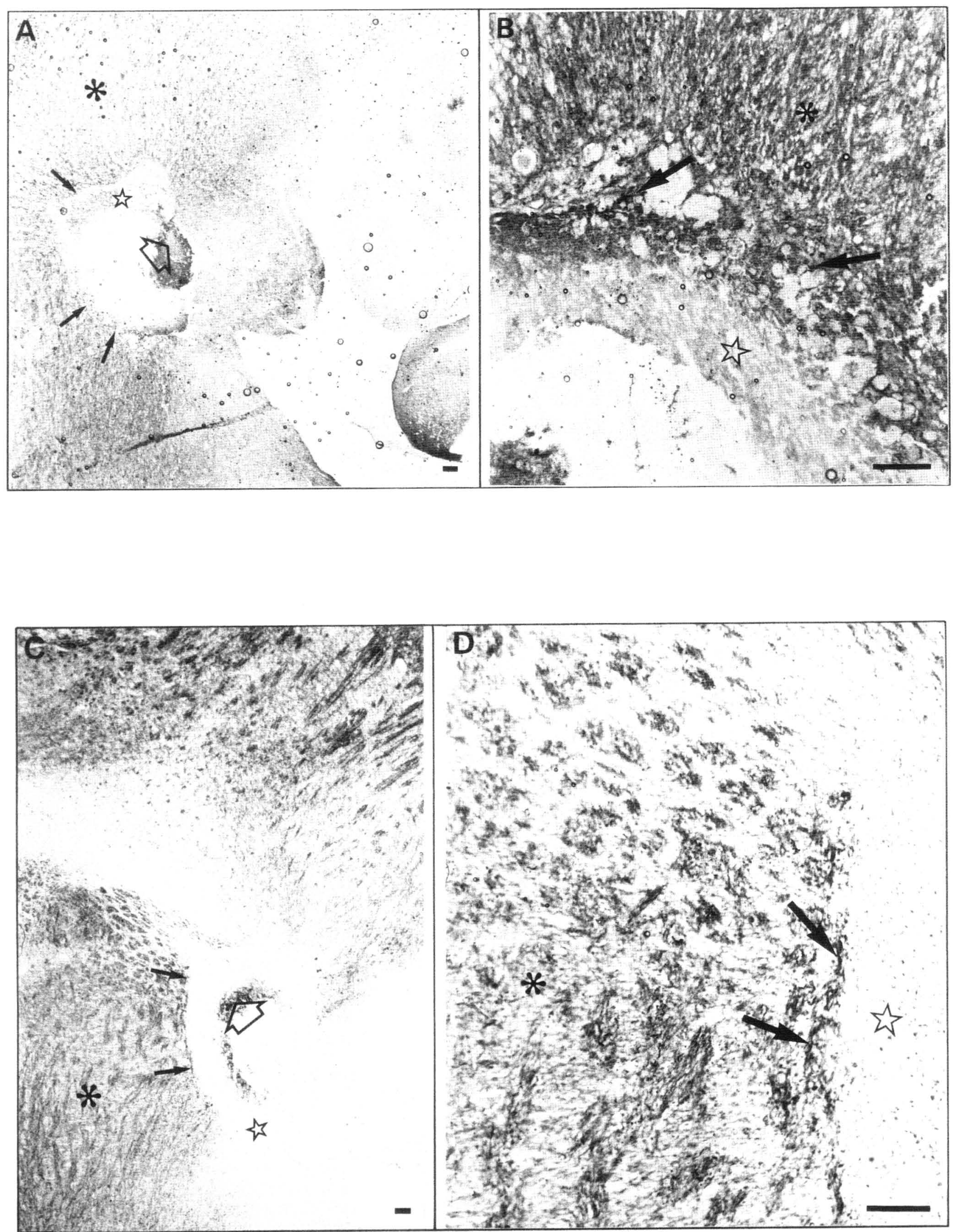


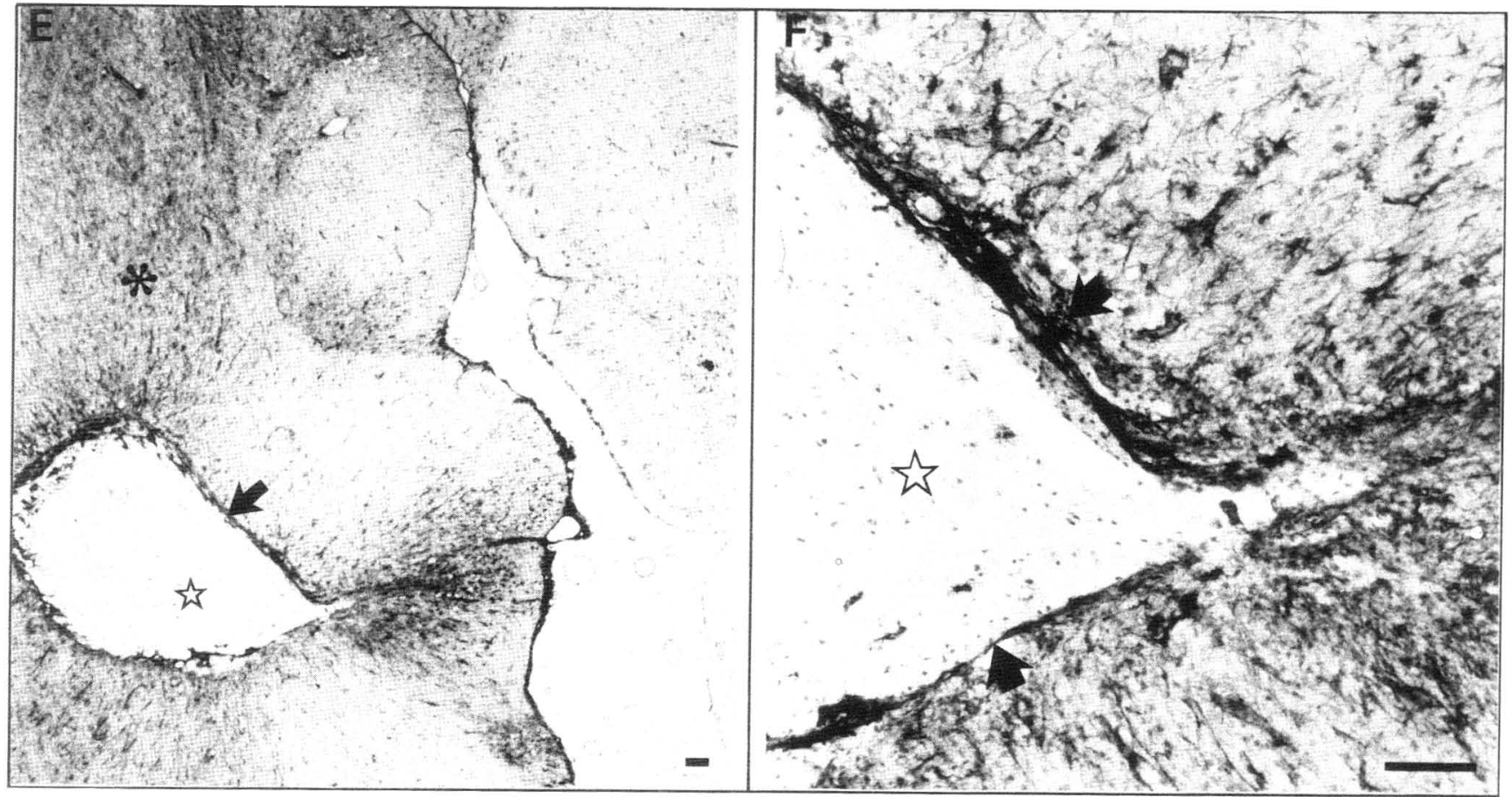

\section{SEE ABOVE AND FACING PAGE}

FIG. 4. Immunodistribution of B-50, NF and GFAP 28 days postlesion in contrastained sections, except for B-50. As shown in panel E, the lesion was outlined by a border of fibers of GFAP staining astrocytes (see also F). In central part of the lesion, there was still accumulation of BIR (arrow outline) separated by the decaying cells (open stars in Fig. 4A and B). At the rim of intact tissue, BIR was seen in neuropil, and a few profiles resembling fibers (B, black arrows). The distribution of NFIR (Fig. 4C) was similar to BIR (B), degenerating material in the center (arrow outline) and some intense staining in fibers at the rim of the lesion (D, black arrows). From hereon the intact tissue (black star) displayed the fiber-like pattern of NFIR, rather similar to the contralateral side. Bar is $100 \mu \mathrm{m}$.

aptations in neuronal circuits distant from the lesion rim were beyond detection. Even at 28 days postsurgery some BIR and NFIR were retained in the very center of the lesion (Fig. 4). This suggests that the destroyed tissue isolated in the lesion center is removed very slowly.

\section{DISCUSSION}

Numerous reviews have described the limited regenerative capacity of the majority of axons in the adult mammalian CNS $(10,16,34,38)$. Recently, studies focused on the expression of growth-associated proteins in this respect $(14,28$, 29). B-50 is identical to GAP43 $(2,20)$.

In the present paper we report immunocytochemical changes in distribution of the neuron-specific, growthassociated protein B-50 in the region surrounding the ventral mesencephalic lesion, in samples after various recovery times. These changes were compared to those seen in the distribution of intermediate filament components, NF, as a neuronal and axon outgrowth marker, and GFAP, a marker for astrocytes.

In the rat $\mathrm{CNS}$ B-50 is primarily expressed during development and levels decline with adulthood $(13,40)$. $\mathrm{B}-50 / \mathrm{GAP}-43 / \mathrm{pp} 46$ is a major phosphoprotein in nerve growth cones isolated from fetal and neonatal rat brain $[(6$, 26, 31) Van Hooff et al., to be published in 1988]. Ultrastruc- tural studies have demonstrated that B-50 is localized in nerve terminals in rat hippocampus in situ. B-50 is predominantly present at the plasma membrane of isolated synaptosomes (7), and growth cones (33). Postlesion increases of GAP43 in CNS neurons have been described to occur in the young but not in the adult rat $(14,26)$. In contrast, during postlesion axonal outgrowth in the PNS, the synthesis of B-50/BAP43 was enhanced $(29,30)$.

In studies on regeneration of crush-damaged sciatic nerve in the rat, staining with anti-NF antibodies was shown to detect the very early events in axonal sprouting and regeneration (35). Further studies on the role of B-50 in PNS regeneration, revealed, the BIR was hardly detectable in undamaged nerve. It was highly expressed in newly formed sprouts and colocalized with NIFR detected by the same monoclonal antibody to NF (70-200 kDa subunits) (36). Recent studies of events at the motor endplate, confirmed that BIR is present in the newly formed sprouts and is associated with the presynaptic membrane and the presynaptic vesicles in newly formed motor endplates (37). Collectively, the evidence suggests that increases of BIR may be involved in changes arising from axon outgrowth, new synapses or remodelling synapses. After nerve transsection BIR accumulated at the degenerating motor endplates and remained present for unexpected long times (37). This observation suggests that B-50 in degenerating axons is slowly removed. 


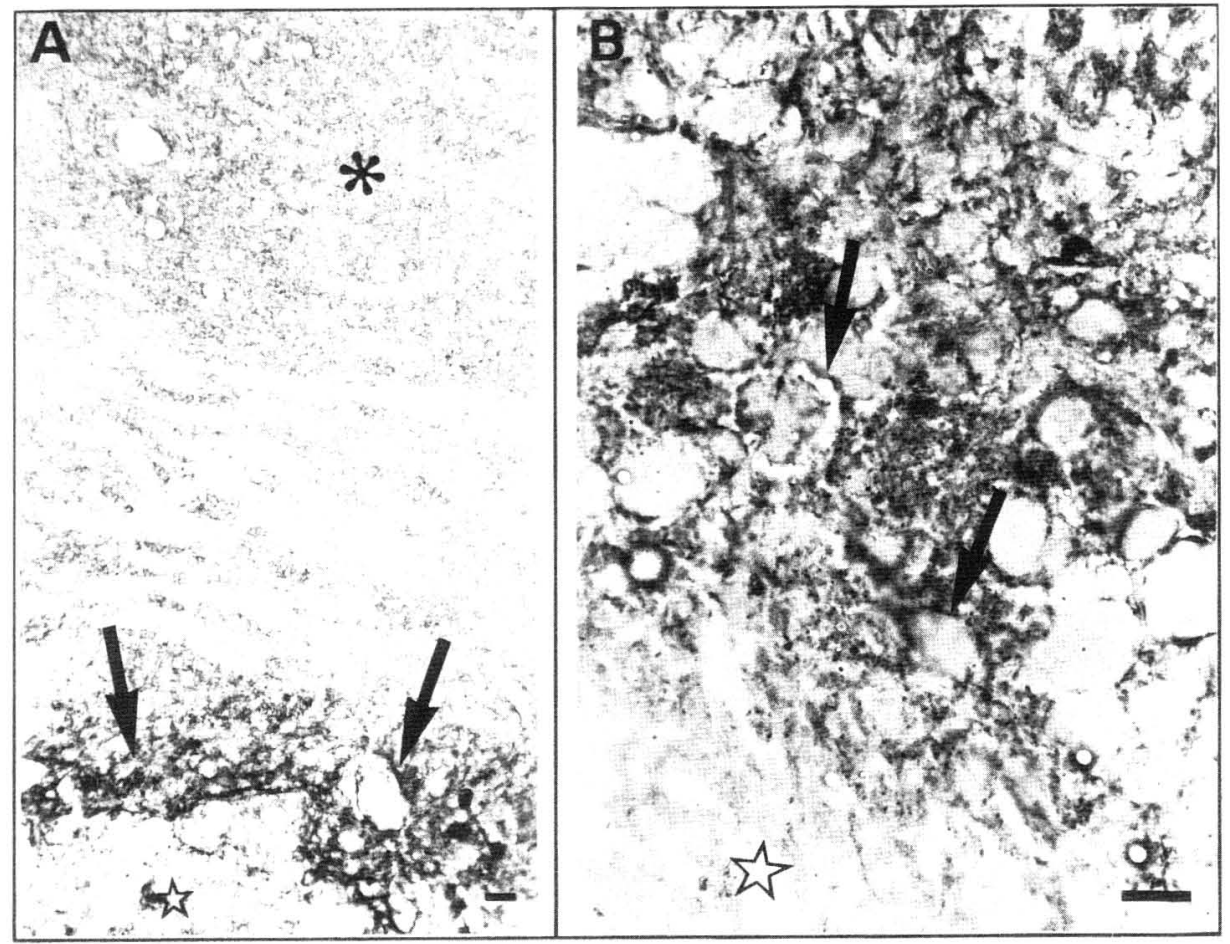

FIG. 5. High magnification photomicrographs taken from noncontrastained sections comparing the $\mathrm{B}-50$ immunodistribution at the rim of the lesion, after 10 (A) and 28 (B) days of survival. The black arrows indicate fiber-like or synaptic structure-like B-50 staining. The open star and the black star are placed in, respectively, disintegrating and intact tissue, the last presenting a normal B-50 immunodistribution. Bar is $10 \mu \mathrm{m}$ in $\mathrm{A}$ and equal to $16 \mu \mathrm{m}$ in B.

Hence increases in BIR in debris may reflect degeneration. whereas BIR accumulation in fibers may indicate regeneration.

In agreement with classical studies [e.g., (39)] we found that during the first postoperative days the apparent lesion size increased as injured cells died and cells were phagocytized (Fig. 1). During the next postoperative period, 3 to 10 days, the size of the affected brain region enlarged only very little. By 28 days, the lesion had contracted and a central cavity incapsulated by astroglia and their processes was formed.

At time points sampled, material in the lesion center displayed BIR, and at 10 and 28 days postlesion also NFIR (specimens from animals sacrificed at earlier time periods were not examined for changes in NFIR). This stained material of the lesion center looked coagulated (induced by the heat of the electrolytic lesion) and showed no structure. Resorption of this burned immunoreactive tissue was slow, presumably as a result of complete destruction of the tissue and impeded accessibility to phagocytotic cells. These results are in line with the idea that increases of BIR and NFIR are not always associated with regeneration, but may be due to slow removal of denatured material containing B-50 and NF [cf. (37) Verhaagen et al., to be published in 1988].

Starting from day 3 onward, the burned immunoreactive center material became separated by a "halo" of immunonegative disintegrating cells from the unaffected surrounding tissue. The tissue of the "halo" appeared to undergo fast degeneration. Both BIR and NFIR disappeared prior to completion of the glial lining of the lesion. Only a few im- munoreactive astrocytes were found in necrotic areas, themselves, and hardly any in the destroyed tissue of the lesion center.

At 10 days postlesion the halo of disintegrating tissue was connected to the rim of uninjured tissue by a few areas. Although the activation of astrocytes may have started much earlier (3) at 10 days postlesion an increased response to anti-GFAP was detected at the rim of the lesion and in other nearby regions. At this time, enhanced NFIR emerged in some cell bodies and fibers (Fig. 3D,E,F) at the lesion rim. In contrast, the increase in BIR was only in fiber-like structures (Fig. 3A,B,C). By 28 days the astroglial response had encapsulated the lesion center (18). At that time, the astrocytic response may have stabilized the surrounding tissue by compensating for the architectural disruption brought about by the lesion. The initial increase in the lesion size and the astroglial response can be taken as responses of degeneration and reaction to injury. Studies indicate that in response to a CNS lesion synapses are lost during the first days postlesion and replaced gradually depending on injury and type of evoked growth $(4,5)$. Several of these studies are documented by electron microscopy and counting synapses. Following unilateral ablation of the entorhinal cortex in the rat, initial loss of most synapses in the outer two-thirds of the dendritic tree of the granule cells at the lesion side has been found. The synaptic density returned to normal levels over a long time period (60-180 days). This recovery process has been described as reactive synaptogenesis, involving axonal sprouting and synapse formation by remaining afferents $(4$, 
5, 11). Our study was restricted to immunocytochemistry, observed by light microscopy and this limits possibilities to distinguish various processes, such as de- and regeneration of fibers and synapses. The time period of recovery for 28 days would allow the start of axonal sprouting of uninjured fibers adjacent to the denervated zone.

For distinguishing between de- and regenerative processes, at the level of our analysis, we proposed that high immunoreactivity (IR) for B-50 and NF in conjunction with unstructured material would suggest that degenerative processes are the dominating aspects in postlesion plasticity. $\mathrm{Re}$ generative processes become dominating when increased BIR and NFIR are present in light microscopic defined fibers. At 10 and 28 days postlesion, we detected enhanced BIR and NFIR at the rim of the denervated zone, arising from the uninjured fiber network with characteristic normal immunostaining. On basis of structural resemblance to fibers, we suggest that the increased BIR and NFIR may be associated with reactive synaptogenesis. It may be that postlesion plasticity as shown by changes in neuronal mark- ers at the lesion rim contributes to the changes observed in the postlesion behavior of these rats (Isaacson et al., to be published in 1988).

In conclusion, the present study shows that the growthassociated protein B-50 is detectable in apparent neuritic sprouts around a lesion in the mesencephalon. The studied neuronal and glial markers changed over time in the area of the lesion. In view of limitations of light microscopic resolution these changes cannot be attributed specifically to components and processes of de- and regeneration.

\section{ACKNOWLEDGEMENTS}

We wish to thank Ruud J. Bloemen and Jan Brakkee for their expert technical assistance. We are grateful to Ed Kluis and Frits Kindt for preparing the figures and to Lia Claessens and MarieJeanne Mens for editing the manuscript. P. Devay is recipient of a European Science Foundation Fellowship which supported this work.

\section{REFERENCES}

1. Altar, C. A.; Marien, M. R.; Marshall, J. F. Time course of adaptations in dopamine biosynthesis, metabolism, and release following nigrostriatal lesions: implications for behavioral recovery from brain injury. J. Neurochem. 48:390-399; 1987.

2. Benowitz, L. I.; Routtenberg, A. A membrane phosphoprotein associated with neural development, axonal regeneration phospholipid metabolism, and synaptic plasticity. Trends Neurosci. 10:527-532; 1987

3. Bignami, A.; Dahl, D. The astroglial response to stabbing. Immunofluorescence studies with antibodies to astrocyte-specific protein (GFA) in mammalian and submammalian vertebrates. Neuropathol. Appl. Neurobiol. 2:99-110; 1976.

4. Cotman, C. W.; Nieto-Sampedro, M.; Harris, E. W. Synapse replacement in the nervous system of adult vertebrates. Physiol. Rev. 61:684-784; 1981.

5. Cotman, C. W.; Nieto-Sampedro, M. Biology of synaptic plasticity. Science 225:1287-1294; 1984.

6. De Graan, P. N. E.; Van Hooff, C. O. M.; Tilly, B. C.; Oestreicher, A. B.; Schotman, P.; Gispen, W. H. Phosphoprotein B-50 in nerve growth cones from fetal rat brain. Neurosci. Lett. 61:235-241; 1985 .

7. Gispen, W. H.; Leunissen, J. L. M.; Oestreicher, A. B.; Verkleij, A. J.; Zwiers, H. Presynaptic localization of B-50 phosphoprotein: the ACTH-sensitive protein kinase substrate involved in rat brain phosphoinositide metabolism. Brain Res. 328:381-385; 1985.

8. Gispen, W. H.; De Graan, P. N. E.; Chan, S. Y.; Routtenberg, A. Comparison between the neural acidic proteins B-50 and F1. Prog. Brain Res. 69:383-386; 1986.

9. Gorgels, Th. G. M. F.; Oestreicher, A. B.; De Kort, E. J. M.; Gispen, W. H. Immunocytochemical distribution of the protein kinase C substrate B-50 (GAP43) in developing rat pyramidal tract. Neurosci. Lett. 83:59-64; 1987.

10. Harvey, A. R.; Gan, S. K.; Dyson, S. E. Regrowth of retinal axons after lesions of the brachium and pretectal region in the rat. Brain Res. 368:141-147; 1986.

11. Hoff, S. F. Lesion-induced transneuronal plasticity in the adult rat hippocampus. Neuroscience 19:1227-1233; 1986.

12. Hsu, S. M.; Raine, I.; Fanger, H. Use of avidin-biotinperoxidase complex (ABC) in immunoperiodate techniques. A comparison between $\mathrm{ABC}$ and unlabeled antibody (PAP) procedures. J. Histochem.Cytochem. 29:577-586; 1981.
13. Jacobson, R. D.; Virag, I.; Skene, J. H. P. A protein associated with axon growth, GAP43, is widely distributed and developmentally regulated in rat CNS. J. Neurosci. 6:1843-1855; 1986.

14. Kalil, K.; Skene, J. H. P. Elevated synthesis of an axonallytransported protein correlates with axon outgrowth in normal and injured pyramidal tracts. J. Neurosci. 6:2563-2570; 1986.

15. Katzman, R.; Björklund, A.; Owman, C. H.; Stenevi, U.; West, K. A. Evidence for regenerative axon sprouting of central catecholamine neurons in the rat mesencephalon following electrolytic lesions. Brain Res. 25:579-596; 1971.

16. Kiernan, J. A. Hypotheses concerned with axonal regeneration in the mammalian nervous system. Biol. Rev. 54:155-197; 1979.

17. König, J. F. R.; Klippel, R. A. The rat brain, a stereotaxic atlas of the forebrain and lower parts of the brain stem. Baltimore: Williams and Wilkins; 1967.

18. Mathewson, A. K.; Berry, M. Observations on the astrocyte response to a cerebral stab wound in adult rat. Brain Res. 327:61-69; 1985.

19. Meiri, K. F.; Pfenninger, K. H.; Willard, M. B. Growthassociated protein, GAP43, a polypeptide that is induced when neurons extend axons, is a component of growth cones and corresponds to pp46, a major polypeptide of a subcellular fraction enriched in growth cones. Proc. Natl. Acad. Sci. USA $83: 3537-3541 ; 1986$.

20. Nielander, H. B.; Schrama, L. H.; Van Rozen, A. J.; Kasperaitis, M.; Oestreicher, A. B.; De Graan, P. N. E.; Gispen, W. H.; Schotman, P. Primary structure of the neuron-specific phosphoprotein B-50 is identical to growth-associated protein GAP-43. Neurosci. Res. Comm. 1:163-172; 1987.

21. Oestreicher, A. B.; Zwiers, H.; Gispen, W. H.; Roberts, S. Characterization of infant rat cerebral cortical membrane proteins phosphorylated in vivo: Identification of the ACTHsensitive phosphoprotein B-50. J. Neurochem. 39:683-692; 1982.

22. Oestreicher, A. B.; Gispen, W. H. Comparison of the immunocytochemical distribution of the phosphoprotein B-50 in the cerebellum and hippocampus of immature and adult rat brain. Brain Res. 375:267-279; 1986.

23. Oestreicher, A. B.; Van Dongen, C. J.; Zwiers, H.; Gispen, W. H. Affinity-purified anti-B-50 protein antibody: interference with the function of the protein B-50 in synaptic plasma membranes. J. Neurochem. 41:331-340; 1983. 
24. Paxinos, G.; Watson, C. The rat brain in stereotaxic coordinates. Sidney: Academic Press; 1982.

25. Perrone-Bizzozero, N. I.; Finklestein, S. P.; Benowitz, L. Synthesis of a growth-associated protein by embryonic rat cerebrocortical neurons in vitro. J. Neurochem. 6:3721-3730; 1986.

26. Pfenninger, K. F. Of nerve growth cones, leukocytes and memory: second messenger systems and growth-regulated proteins. Trends Neurosci. 9:562-565; 1986.

27. Pritzel, M.; Huston, J. P.: Sarter, M. Behavioral and neuronal reorganization after unilateral substantia nigra lesions: evidence for increased interhemispheric nigrostriatal projections. Neuroscience 9:879-888; 1983 .

28. Reh, T. A.: Redshaw, J. D.: Bisby, M. A. Axons of the pyramidal tract do not increase their transport of growth-associated proteins after axotomy. Mol. Brain Res. 2:1-6; 1987.

29. Skene, J. H. P.; Willard, M. Changes in axonally transported proteins during axon regeneration in toad retinal ganglion cells. J. Cell Biol. 89:86-95; 1981.

30. Skene, J. H. P.; Willard, M. Axonally transport proteins associated with axon growth in rabbit central and peripheral nervous systems. J. Cell Biol. 89:96-103; 1981.

31. Skene, J. H. P.; Jacobson, R. D.; Snipes, G. J.; McGuire, C. B.: Norden, J. J.; Freeman, J. A. A protein induced during nerve growth, "GAP-43", is a major component of growth-cone membranes. Science 233:783-786; 1986.

32. Van Hooff, C. O. M.: De Graan, P. N. E.: Boonstra, J.: Oestreicher, A. B.; Schmidt-Michels, M. H.; Gispen, W. H. Nerve growth factor enhances the level of the protein kinase $\mathrm{C}$ substrate B-50 in pheochromocytoma PCI2 cells. Biochem. Biophys. Res. Commun. 139:644-651; 1986.

33. Van Lookeren-Compagne, M.; Oestreicher, A. B.; Van Bergen en Henegouwen, P. M. P.; Verkleij, A. J.; Gispen, W. H. Immunocytochemical distribution of the phosphoprotein B-50 in isolated presynaptic nerve terminals and growth cones. Proc. Dutch Fed. Meet. 20:241; 1988.
34. Veraa, R. P.: Grafstein, B. Cellular mechanisms for recovery from nervous system injury: a conference report. Exp. Neurol. $71: 6-75: 1981$

35. Verhaagen, J.; Edwards, P. M.; Jennekens, F. G. I.; Schotman, P.: Gispen. W. H. Study on the neurotrophic action of an ACTH(4-9) analog (Org. 2766) on nerve fiber outgrowth using neurofilament-binding antibodies. Neurosci. Lett. [Suppl] 26:184: 1986.

36. Verhaagen, J.; Van Hooff, C. O. M.; Edwards, P. M.; De Graan, P. N. E.; Oestreicher, A. B.; Schotman, P.; Jennekens, F. G. I.; Gispen, W. H. The kinase C substrate protein B-50 and axonal regeneration. Brain Res. Bull. 17:737-741; 1986.

37. Verhaagen, J.; Oestreicher, A. B.; Edwards, P. M.; Veldman, H.; Jennekens, F. G. I.; Gispen, W. H. Light and electron microscopical study of phosphoprotein B-50 following denervation and reinnervation of the rat neuromuscular junction. 1st Eur. Conf. Myastenia Gravis Maastricht; 101; 1987.

38. Windle, W. F. Regeneration of axons in the vertebrate central nervous system. Physiol. Rev. 36:426-440; 1956.

39. Wolf, G.: DiCara, L. V. Progressive morphologic changes in electrolytic brain lesion. Exp. Neurol. 23:529-536; 1969.

40. Zwiers, H.: Oestreicher, A. B.; Bisby, M. A.: De Graan, P. N. E.; Gispen, W. H. Protein kinase C substrate B-50 in adult and developing rat brain is identical to axonally-transported GAP43 in regenerating peripheral rat nerve. In: Bisby, M. A.; Smith, R. S., eds. Axonal transport. New York: Alan Liss, Inc.: 1987:421-433 